factor for deep vein thrombosis in women in Glasgow. British Journal of Haematology, 112, 641

ROSZLER, M. H., MCCARROLL, K. A., DONOVAN, K. R., et al (1989) The groin hit: complications of intravenous drug abuse. Radiographics, 9, 487 508

WILLIAMS, P. G., ANSELL, S. M. \& MILNE, F. J. (1997) Illicit intravenous drug use in Johannesburg - medical complications and prevalence of HIV

infection. South African Medical Journal, 87, 889-891.

Karen Williams Consultant Psychiatrist, AddictionTreatment Unit, Gloucester, *Emma Abbey Specialist Registrar, Wotton Lawn Hospital, Horton Road, Gloucester GL1 3WL, e-mail: emma.abbey@glos.nhs.uk

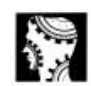

original papers

\title{
Driving, dementia and the Driver and Vehicle Licensing Agency: a survey of old age psychiatrists
}

\section{AIMS AND METHOD}

We surveyed old age psychiatrists in the north-east of England to determine what they considered relevant indicators of driving ability. The survey asked about their satisfaction with the current Driver and Vehicle Licensing Agency (DVLA) procedure of assessing competence to drive in patients with dementia and how they thought this could be improved.

\section{RESULTS}

Fifty-seven out of 76 psychiatrists (75\%) responded; 26 (45\%) respondents thought the forms issued by the DVLA were unsatisfactory but 32 $(57 \%)$ were satisfied with the eventual decisions made about individual patients. Factors thought to be relevant indicators of driving ability were occupational therapy $(n=46,81 \%)$, neuropsychological assessments ( $n=43,75 \%)$ and carer's report of driving $(n=48,84 \%)$. Factors thought not to be relevant were patient's report of driving ability ( $n=13,23 \%)$ and the Mini Mental State Examination ( $n=21,38 \%)$.

\section{CLINICAL IMPLICATIONS}

The current system for determining driving ability in people with cognitive impairment and dementia was felt to be unsatisfactory. A multidisciplinary approach and use of onroad driving assessments may improve decision-making.
Over two million people over the age of 70 hold a current driving licence in the UK and this is estimated to increase to four and a half million by 2013 (Department of Transport, 2001). Since age is an important risk factor for dementia the number of drivers with dementia is expected to increase. A retrospective analysis of referrals to a memory clinic in Somerset revealed that 20\% were still driving (Kolowski \& Rossiter, 2000). A brief analysis of 250 police reports of accidents in 1995 showed that dementia was the most common psychiatric disorder when disability or illness was implicated as a cause (Harris, 2000). Although it is important to consider the risks of driving for people with dementia, it is also important to make appropriate decisions since cessation of driving can have a significant negative impact on the patient and their family (Taylor \& Tripodes, 2001) and driving skills can be retained in the early stages of dementia.

In the UK only the Driver and Vehicle Licensing Agency (DVLA) holds statutory responsibility for decisions on whether a person can hold a driver's licence but most decisions are based on medical reports (British Psychological Society, 2001). There are no specific forms for drivers with cognitive impairment and medical reports for drivers with dementia are usually completed on forms issued for neurological impairment. There are no clinical tests available to predict driving ability in patients with cognitive impairment. On-road assessments have been described as a more reliable method (Lloyd et al, 2001; Dobbs et al, 2002).
There are few studies from the UK on the driving ability of patients with dementia. We surveyed old age psychiatrists in the north-east of England and the Borders to determine what they considered relevant indicators of driving ability and how often driving assessments were used. The survey also looked at their satisfaction with the current procedure of assessing competence to drive in patients with dementia and how they thought this could be improved.

\section{Method}

A questionnaire was sent to 76 old age psychiatrists who are registered to attend the Northern Regional Old Age Psychiatry Meeting which is held four times a year. This included consultants, specialist registrars and non-career grade doctors working in the counties of Tyne and Wear, Durham, Northumberland, Cumbria, Dumfriesshire and Teeside. The questionnaire asked respondents to agree or disagree with a list of statements (Box 1). Space was also available for comments. We included statements taken directly from the forms issued by the DVLA for drivers with cognitive impairment (Neuro 2C), to determine what respondents thought were relevant indicators of driving ability.

The questionnaire was piloted and changes were made to ease completion. It was then sent to the above group and a further copy was sent 2 weeks later to improve response rates. 
Box 1. Statements/questions taken from the questionnaire sent to old age psychiatrists in the north-east of England

original

papers
- How many DVLA medical assessment forms have you completed in the past 6 months?

- The medical assessment forms issued by the DVLA for drivers with cognitive impairment are satisfactory.

- The decisions made by the DVLA on drivers with cognitive impairment are usually appropriate.

- Have you ever contacted the DVLA directly about a patient's driving ability?

- In your opinion the following categories are relevant indicators of driving ability: significant impairment of memory sufficient to cause disorientation ${ }^{1}$

significant loss of judgement ${ }^{1}$

inappropriate behaviour ${ }^{1}$

type of dementia

carer's report of driving ability

patient's report of driving ability

brief cognitive assessments, e.g. MMSE

occupational therapy assessment

detailed neuropsychological battery.

- What additional history/items do you think are relevant?

- Have you referred a patient with cognitive impairment to a driving assessment centre?

- How many have you referred in the past year?

- How do you feel the DVLA forms could be improved?

- Do you have any suggestions as to how assessments and decisions about driving could be improved?

DVLA, Driver and Vehicle Licensing Agency; MMSE, Mini Mental State Examination.

1. Taken from the medical forms issued by the DVLA relating to cognitive impairment.

\section{Results}

The response rate was $75 \%$ (57 out of 76), with responses from 38 consultants $(67 \%), 10$ specialist registrars (18\%), 8 staff grade doctors (14\%) and 1 associate specialist.

Thirty-six respondents (63\%) had filled in forms issued by the DVLA in the previous 6 months, 25 (44\%) had filled in one to three forms and the rest had completed between three and ten forms. Twenty-six (45\%) disagreed with the statement that the forms were satisfactory.

Thirty-two doctors (57\%) agreed (4\% strongly and $53 \%$ agreed) that decisions made by the DVLA regarding drivers with cognitive impairment were satisfactory (Table 1); 37 respondents (65\%) had directly contacted the DVLA because of concerns about a patient's driving

Fifty respondents (88\%) were aware of specialist driving centres where drivers with dementia could undertake a driving assessment and 38 (66\%) had referred patients for an assessment. In the previous year $29(50 \%)$ had referred $1-3$ patients to such a centre but only 3 respondents had referred more than 3 patients.

Table 2 summarises categories thought to be relevant indicators of driving. The categories of cognitive
Box 2. The most common comments made by respondents

The medical assessment forms for drivers with cognitive impairment are satisfactory

- Unclear what is required

- Forms geared towards neurological impairment

- Forms not specific or relevant to dementia

- Do not measure level or degree of impairment

- No space for free text

- No guidance on what criteria to use or what 'significant' means

Decisions made by the DVLA are usually appropriate

- Based on diagnosis rather than skills

- Too cautious

- Toolenient

- Insensitive in communicating decisions to family

- Decision based on minimal information

What additional history/items are relevant

- History of accidents/near misses

- Lack of insight/judgement

- Visuospatial skills

- Current medication

- Carer's report

- Type of driving

- Use of alcohol

- Physical illness

- Degree of cognitive impairment

- Functional assessment

How do you feel the DVLA medical assessment forms could be improved?

- Forms specific to dementia

- Guidance on what 'significant' means and on what criteria to use

- Space for free text

- More comprehensive forms including questions on visuospatial skills, carer's report and executive function

Do you have any suggestions as to how assessments and decisions about driving might be done?

- Driving assessments

- Multidisciplinary approach including occupational therapists and neuropsychological assessments

- Driving simulators

- Assessments should be done by the DVLA or specialist assessment centres

- Information from DVLA on what to look for

DVLA, Driver and Vehicle Licensing Agency.

impairment used on the form issued by the DVLA were thought to be relevant indicators by more than $80 \%$ of the respondents. A carer's report of driving ability was considered to be more relevant than a patient's report. Occupational therapy and neuropsychological testing were considered to be relevant indicators by more than $80 \%$ of the respondents. Mini Mental State Examination score (MMSE; Folstein et al, 1975) was not widely thought to be a relevant indicator of driving ability.

Box 2 lists the most common comments of respondents in response to questions and statements from the survey. 


\begin{tabular}{|lcrrrr} 
& \multicolumn{3}{c}{ Response, $n(\%)$} \\
\cline { 2 - 6 } & Strongly agree & Agree & Neither & Disagree & Strongly disagree \\
\hline Medical assessment forms are satisfactory & $0(0)$ & $9(16)$ & $12(21)$ & $17(30)$ & $9(16)$ \\
Decisions are usually appropriate & $2(4)$ & $30(53)$ & $11(19)$ & $10(18)$ & $0(0)$ \\
\hline
\end{tabular}

DVLA, Driver and Vehicle Licensing Agency.

Table 2. Opinions of 57 old age psychiatrists regarding relevant indicators of driving ability

\begin{tabular}{|c|c|c|c|c|c|}
\hline \multirow[b]{2}{*}{ Indicators of driving ability } & \multicolumn{5}{|c|}{ Response, n (\%) } \\
\hline & Strongly agree & Agree & Neither & Disagree & Strongly disagree \\
\hline Significant loss of judgement & $37(65)$ & 18 (3) & $1(2)$ & $0 \quad(0)$ & $0 \quad(0)$ \\
\hline Alzheimer's disease & $6(11)$ & $11(19)$ & $18(32)$ & $16(28)$ & $2(4)$ \\
\hline Vascular dementia & $6(11)$ & $10(18)$ & $19(34)$ & $16(28)$ & $4(7)$ \\
\hline Frontotemporal dementia & $12(21)$ & $14(25)$ & $14(25)$ & $12(21)$ & $3(5)$ \\
\hline Dementia of Lewy bodies & $11(19)$ & $11(19)$ & $16(28)$ & $13(23)$ & $4(7)$ \\
\hline Carer's report of driving ability & $18(32)$ & $30(53)$ & 5 (9) & $3(5)$ & $0 \quad(0)$ \\
\hline Occupational therapy assessment & $8(14)$ & $38(67)$ & $6(11)$ & $4(7)$ & $0 \quad(0)$ \\
\hline Detailed neuropsychological battery & $7(12)$ & $36(64)$ & $10(18)$ & $2(4)$ & $0 \quad(0)$ \\
\hline
\end{tabular}

\section{Discussion}

Driving and cognitive impairment remains an understudied area and there are no clinical tests of cognitive impairment that closely correlate with or can accurately predict driving ability (Withaar et al, 2000; Dobbs et al, 2002). This issue will increase in significance as the population ages and may be complicated by the use of cholinesterase inhibitors, which may slow disease progression.

Respondents thought the current forms issued by the DVLA for drivers with dementia were unsatisfactory and were directed towards neurological impairment rather than dementia. The forms do not offer any guidance as to what is 'significant impairment'. Respondents listed degree of insight, medication and alcohol misuse as relevant to the assessment of driving. These items are present on forms issued by the DVLA for psychiatric disorders but not on the forms issued for neurological impairment, which are generally used.

If forms were developed specifically for dementia or current forms made more detailed, this could increase the time needed for their completion. This might have an impact on doctors' workload since $63 \%$ of respondents had filled in forms over the previous 6 months. However, several doctors commented that they already send written reports to supplement the existing forms, which explains why, despite the dissatisfaction expressed with the medical assessment forms, the decisions made by the DVLA were thought to be appropriate. Several respondents wondered to what extent treating doctors should be involved in the process given the negative impact on the therapeutic relationship when a patient is told they can no longer drive. It was suggested that the DVLA or other specialised services might be more involved in this part of the process.

Occupational therapists possess skills in the assessment of physical, visuospatial, cognitive and functional ability that can help in assessment of driving ability (Lloyd et al, 2001). A recent review showed that neuropsychological tests can make a significant contribution to assessment (Reger et al, 2004), but others have shown no correlation between cognitive assessments such as MMSE scores or scores on the Clinical Dementia Rating Scale (Hughes et al, 1982) and driving ability (Lloyd et al, 2001; Dobbs et al, 2002). A multidisciplinary approach involving occupational therapists and neuropsychologists in the assessment could improve decision-making.

On-road assessment, particularly standardised tests such as the Washington University Road Test (Hunt et al, 1997), have been described as more accurate indicators of driving ability than surrogate assessments. In the UK, drivers with dementia have to be referred to mobility centres for assessment of their driving skills, as there are no specialist assessment centres for dementia. There are only 16 such centres in the UK (only one in the north-east original papers 
of England), which limits access. Limitations of on-road testing have been described in a recent review and

original papers include risks to the patient and other road users during testing (Brown \& Ott, 2004). Despite this, two-thirds of old age psychiatrists in our sample had referred patients to a driving assessment centre and on-road driving assessments were the most popular suggestion as how to assess driving ability.

\section{Conclusion}

The current system for determining driving ability of patients with cognitive impairment and dementia was considered unsatisfactory. More guidance is needed from the DVLA on what criteria to use for people with dementia and specific forms would be helpful. A multidisciplinary approach with participation of occupational therapists and psychologists and the use of on-road driving assessments may improve decision-making.

\section{Declaration of interest}

None.

\section{Acknowledgements}

We thank the doctors who took part in the survey and Drs Briel, Krishnan and Jamir for their comments.

\section{References}

BRITISH PSYCHOLOGICAL SOCIETY (2001) Fitness to Drive and Cognition Leicester: British Psychological Society. BROWN, L. \& OTT, B. (2004) Driving and dementia: a review of the literature. Journal of Geriatric Psychiatry and Neurology, 17, 232-240.

DEPARTMENT OF TRANSPORT (2001) Older Drivers: A Literature Review. London: Department of Transport.

DOBBS, B., CARR, D. \& MORRIS, J. (2002) Evaluation and management of the driver with dementia. Neurologist, 8, 61-70.

FOLSTEIN, M. F., FOLSTEIN, S. E. \& McHUGH, P. R. (1975) 'Mini-menta state'. A practical method for grading the cognitive state of patients for the clinician. Journal of Psychiatric Research, 12, 189-198.

HARRIS, M. (2000) Psychiatric conditions with relevance to fitness to drive. Advances in Psychiatric Treatment, 6, 261-269.

HUGHES, C. P., BERG, L., DANZIGER, W. L., et al (1982) A new clinical scale for the staging of dementia. British Journa of Psychiatry, 140, 566- 572.

HUNT, L. A., MURPHY, C. F., CARR, D. University Road Test: a performance based assessment for drivers with dementia of the Alzheimer type. Archives of Neurology, 54,707-712.

KOLOWSKI, S. J. \& ROSSITER, J. (2000) Driving in Somerset. Psychiatric Bulletin, 24, 304-306.

LLOYD, S., CORMACK, C., BLAIS, K., et al (2001) Driving and dementia: a review of the literature. Canadian Journal of Occupational Therapy, $6 \mathbf{8 .}$ 149-155.

REGER, M., WELSH, R. K., WATSON, G. S., et al (2004) The relationship between neuropsychological function and driving ability in dementia: a metaanalysis. Neuropsychology, 18 85-93.

TAYLOR, B. D. \& TRIPODES, S. (2001) The effects of driving cessation on the elderly with dementia and their caregivers. Accident Analysis and Prevention, 33, 519-528.

WITHAAR, F. K., BROUWER, W. H. \& VANZOMERAN, A. H. (2000) Fitness to drive in older drivers with cognitive impairment. Journal of the International Neuropsychological Society, 6, 480-490. et al (1997) Reliability of theWashington

*Anitha Naidu Specialist Registrar in Old Age Psychiatry, Bensham Hospital Saltwell Road, Gateshead NE4 OBE, e-mail: dranithanaidu@gmail.com, Ian G. McKeith Professor of Old Age Psychiatry, Institute for Ageing and Health, Wolfson Research Centre, Newcastle General Hospital, Westgate Road, Newcastle uponTyne 